Article

\title{
An In-Depth Analysis of Parking Patterns in a Typical Chinese Danwei via Customized Data Collection App
}

\author{
Wenyuan Kong ${ }^{1,2}\left(\mathbb{D}\right.$, Caiying Liao ${ }^{3}\left(\mathbb{D}\right.$, Qian $\mathrm{Xu}^{4}$, Jiabei Wang ${ }^{5}$ and Teng Fei ${ }^{2, *(1)}$ \\ 1 School of Earth and Space Sciences, Peking University, Beijing 100871, China; kongwenyuan@pku.edu.cn \\ 2 School of Resource and Environmental Sciences, Wuhan University, Wuhan 430079, China \\ 3 State Key Laboratory of Information Engineering in Surveying, Mapping and Remote Sensing, \\ Wuhan University, Wuhan 430079, China; caiying.liao@whu.edu.cn \\ 4 Academy for Advanced Interdisciplinary Studies, Peking University, Beijing 100871, China; \\ persistent.xq@pku.edu.cn \\ 5 School of Remote Sensing and Information Engineering, Wuhan University, Wuhan 430079, China; \\ 2016302590068@whu.edu.cn \\ * Correspondence: feiteng@whu.edu.cn
}

check for updates

Citation: Kong, W.; Liao, C.; Xu, Q.; Wang, J.; Fei, T. An In-Depth Analysis of Parking Patterns in a Typical Chinese Danwei via Customized Data Collection App. ISPRS Int. J. Geo-Inf. 2021, 10, 567. https://doi.org/ $10.3390 /$ ijgi10080567

Academic Editor: Wolfgang Kainz

Received: 2 June 2021

Accepted: 20 August 2021

Published: 23 August 2021

Publisher's Note: MDPI stays neutral with regard to jurisdictional claims in published maps and institutional affiliations.

Copyright: (c) 2021 by the authors. Licensee MDPI, Basel, Switzerland. This article is an open access article distributed under the terms and conditions of the Creative Commons Attribution (CC BY) license (https:// creativecommons.org/licenses/by/ $4.0 /)$.

\begin{abstract}
The danwei is a distinctive spatial unit in China, as a legacy of the Maoist era. In a danwei, state-owned enterprises supplied a full set of facilities, such that people's daily activities did not often extend beyond their danweis. However, with the rapid alteration of civic social space in Chinese cities, many employees are no longer tied to a particular danwei. Traditional Chinese danweis have suddenly been faced with a shortage of car-parking space. In the context of the municipal call for danweis to "dismantle the walls and open up for traffic microcirculation", this study aims to propose a practical approach that analyzes the parking status in a typical danwei. Based on both the parking data collected via a self-designed smartphone application and the survey data collected via questionnaires, the approach analyzes the parking situation in terms of four aspects, including hot parking zones, dynamic parking demand, vehicle parking behaviors, and perceptions of the parking situation. We conducted the experiment on the Information Department Campus of Wuhan University, which is a typical Chinese danwei with complicated surroundings. The results indicate non-negligible issues in the current parking situation, such as vulnerabilities in parking resource management, and a contradiction between supply and demand. Based on the results, we recommend possible strategies to alleviate the tense parking situation and we are confident of the feasibility of opening danwei roads first instead of opening parking facilities, as a response to "open up" the danweis. This study may serve as a representative example of how danweis should analyze their current parking situation and how to respond to the municipality's suggestions: using modern technology to conduct data collection, perform in-depth and detailed analysis, and synthesize explicit localized policy.
\end{abstract}

Keywords: parking; campus; traffic microcirculation; danwei; China

\section{Introduction}

In China, the spatial form of Chinese "danwei" (work unit), which composes a city, is a historical legacy [1]. The danwei is an integrated spatial unit of work, residence and social life, enclosed by walls, centered around state-owned enterprises and institutions, creating identity and a sense of belonging in people. Before 1978, nearly every citizen in China was assigned to a danwei. The daily activities of these people did not usually extend beyond their danweis.

Today, the danwei is still a typical organizational unit of Chinese society. There were 21,091,270 danweis in China as of the end of 2019 [2]. In the city of Wuhan, 2.47 million out of 9.06 million permanent residents work in danweis [3]. However, with the rapid development of urban infrastructure as well as the extension of citizens' social spaces in 
the past decades, more and more Chinese employees are no longer tied to a particular danwei, even if they live in one. The prevailing need for daily travel among citizens who live in danweis has led to a rapid increase in the number of private cars and consequently, a sudden if unforeseen shortage of car-parking space in danweis.

At the same time, with the rate of motor vehicle ownership surging in recent years, a serious shortage of parking space has emerged in most Chinese cities [4,5]. To cope with this situation, the State Council recently put forward a proposal that calls on closed communities such as danweis to gradually open up and integrate with the surrounding traffic networks. This policy is expected to improve traffic conditions in cities because the enclosed spaces of danweis cannot be penetrated by current urban road networks, thus resulting in a large number of "cut-off roads" and preventing urban road networks from reaching reasonable spatial density. It is believed that when danweis no longer isolate themselves from their external urban surroundings, smoother urban traffic flow within the city may be possible thanks to the open paths into the danweis, analogous to blood flowing through the capillaries of a living organism.

For a particular danwei, allowing outside vehicles in will certainly put extra pressure on its existing parking facilities. Prior to any action that can be implemented to respond to municipal demand, an in-depth analysis of the current parking situation in danweis needs to be conducted.

However, parking-related issues have been overlooked in China [6] even at the city level [7-10], let alone in the danweis. Few studies have focused on the parking situation in danweis. Though there have been studies of parking status in urban organizational units in other countries [11-14], due to differences in the characteristics of Chinese danweis and other countries' organizations, such as the seamless interconnections between organization infrastructure and public transit systems in western countries, the research methods and parking issues cannot be directly applied to danweis. As a result, a complete and practical framework for the in-depth analysis of danwei parking conditions is urgently needed.

There are two main challenges in proposing a framework for the analysis of danwei parking conditions, i.e., data collection and parking status analysis. To collect data, surveys are widely leveraged [15-19]. For instance, Shannon, Giles-Corti [20] posted letters to 2300 staff and 2200 students in UWA; Meng, Du [21] designed "stated preference" questionnaires and received 1873 valid responses; Gurbuz, Jauregui [22] conducted an internet survey of 208 American universities. In addition, intelligent parking systems are used for data collection, as performed in many studies [23-28]. There are also other ways to collect data, for example, counting the number of vehicles entering and exiting school gates [29]. To analyze parking status, the inflow and outflow of vehicles, the occupancy of parking spaces, etc. are also often examined in existing studies. For example, Shang, Wenji [29] computed the inflow and outflow of vehicles at facility gates and analyzed demand and turnover at six parking lots; Barata, Cruz [30] recorded the vehicle flow through campus gates and estimated the occupancy of pre-classified parking spaces based on several assumptions. Parking status also can be obtained in the form of statistical models [30-33].

Nevertheless, data from surveys are better suited for the analysis of preferences for parking rather than objective parking status, which is consistent with the intrinsic subjective nature of surveys. Collecting data through intelligent parking systems is a helpful approach, but first, the space inside a danwei is often inaccessible for municipal construction; second, the data collected by the intelligent gating systems in Chinese danweis are usually private and unavailable for individual use, and few danweis have intelligent parking monitoring systems that can record parking information for every parking spot. Recording traffic flow manually incurs heavy manpower costs and is not feasible when the area of the danwei is large. Furthermore, data collected from surveys and intelligent parking systems do not include license plate information generally to protect privacy, while collecting parking data manually usually involves recording license plate numbers identified by human monitors, which is very tedious and time-consuming. As for parking status analysis, existing studies 
have mainly considered the usage of parking spaces, without including an analysis of parking patterns (i.e., common parking behaviors).

In this study, we sought to provide a complete and practical framework for the in-depth analysis of danwei parking conditions, examining both the usage of parking spaces and the typical parking patterns. Considering that most danweis do not have either an intelligent parking system or a parking monitoring system such as used by organizations in the United States and European countries, the parking data collected by a danwei are private, and no economical and efficient way yet exists to track the location of each vehicle over time, we present a handy and efficient distributed smartphone application to collect car parking data inside a danwei. This smartphone application records and recognizes the license plate numbers and parking locations of vehicles in near real-time. Additionally, we collected survey data on people's perceptions towards the parking situation via online questionnaires. To analyze the parking situation, first, discrete parking spots were integrated into parking zones. Second, four aspects of parking situation analysis were implemented, including hot parking zone analysis, dynamic parking demand analysis, vehicle parking behavior analysis, and parking situation perception analysis. The density-based clustering method was widely leveraged in the analytical process. To verify the practicability of the method and the validity of the analysis, we conducted a case study. The results could provide insight into the current parking situation inside Chinese danweis and would be a basis for the discussion of parking policies that are designed to improve the parking situation in danweis exemplified by our study area and facilitate wiser decisions on ways to cope with the municipal call to "open up".

\section{Preliminaries}

\subsection{Research Area}

This research was conducted in the Information Department Campus of Wuhan University, which is a typical Chinese danwei. Wuhan University is in Wuhan, Hubei Province, China. The selected campus is one of the four main campuses of the university and covers about 0.9 square kilometers (Figure 1). In recent years, the number of vehicles on the campus has been increasing rapidly. There are three large shopping malls and four roads (Luoyu Road, Luoshi Road, Guangba Road, and the underpass of Bayi Road) with dense traffic flow that surround the campus.

\subsection{Determining the Data Collection Time Window}

Due to the weekly fluctuation in vehicle parking patterns as well as the workload of dynamically monitoring all vehicles on campus, the selected research period lasted for 7 days (14-20 October 2019).

Given that complete data collection of all cars parked on the campus takes about $60 \mathrm{~min}$ for five investigators, a preliminary experiment was conducted to determine the data collection time. We randomly selected four large parking lots with large parking capacity that were evenly distributed across the campus to monitor hourly changes in the number of parked cars on a Wednesday (9 October 2019) and a Saturday (12 October 2019). We concede that there may be problems when generalizing the rules obtained from a small sampled sub-dataset to the overall dataset due to possible sampling bias, and it is of course best to record information for parked vehicles at all hours in a day, but this was impractical under current conditions. Therefore, we selected representative parking lots to identify the possible data collection window and minimize generalization error.

As a result, we identified three time windows when the number of parked cars was rather stable, including 09:00-10:00 (morning), 13:00-14:00 (afternoon), and 20:00-21:00 (evening). Thus, on the 7 sampled days, the data collection times were fixed to these three time windows. 


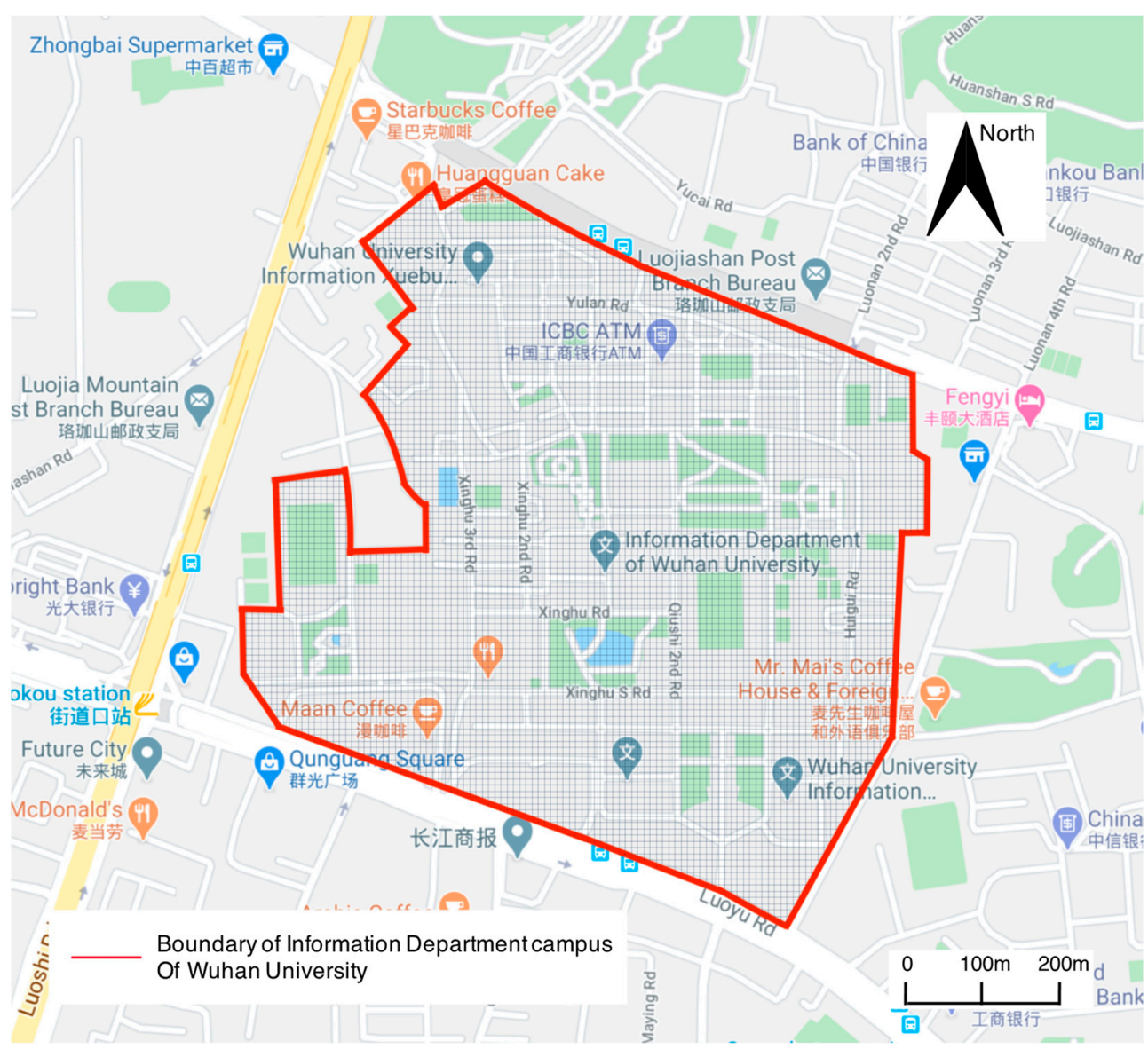

Figure 1. The location of the Information Department Campus of Wuhan University. The source of the map is Google Maps.

\section{Materials and Methods}

The overall research can be divided into three stages, i.e., a data preparation stage, a parking zone partition stage, and a parking analysis stage, as displayed in Figure 2. Specifically, in the data preparation stage, parking data and survey data were collected via a self-designed Android app and online questionnaires, separately. In the parking zone partition stage, both the grid-based parking zone partition approach and the clusterbased parking zone partition approach were proposed. In the parking analysis stage, four aspects of analysis were conducted, i.e., hot parking spot identification based on grid-based parking zones; dynamic parking demand based on both the cluster-based parking zones and self-defined metrics; vehicle categorization based on both the cluster-based parking zones and spatiotemporal parking behaviors; and parking situation perceptions based on survey data.

Finally, with reference to the results of analysis, suggestions were proposed for the management of campus vehicles and the opening of campus transportation facilities to the city. 


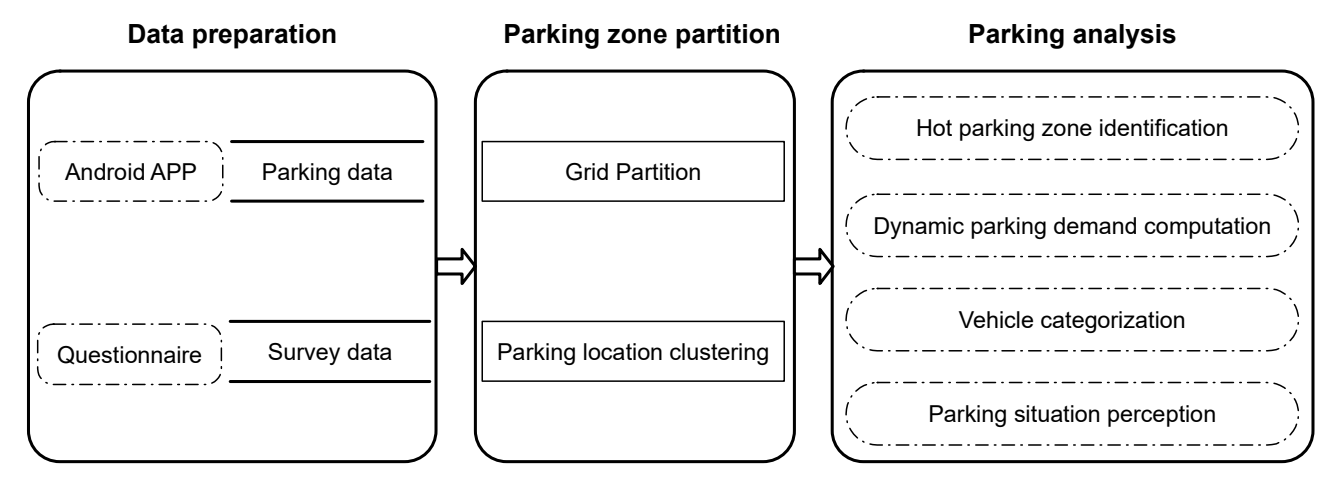

Figure 2. The three sequential stages of the research, including the data preparation stage, the parking zone partition stage and the parking analysis stage.

\subsection{Data Preparation}

Both the parking data and the people's opinions were collected for complementary analysis. With the help of the parking data, the objective parking situation could be examined, while people's opinions could provide perceptual perspectives on the parking situation.

\subsubsection{Parking Data Preparation}

An Android app (https://github.com/Meteoritewhu/Video-GPS (accessed on 22 August 2021)) was designed to collect parking data. The main function of this app is to video while recording the GPS of the parked location, which is updated every second. The start and end time of the video is also recorded.

The application was designed in Android Studio (version 3.4.2) using the 1.8 .0 version of Java JRE on macOS 10.14.6. After the user specifies a file name, with the "Start record" button pushed, the application starts to record a video at 24 frames per second (FPS). In the main GUI, real-time video and GPS information are presented.

As mentioned in Section 2.2, the parking data were collected by 5 investigators. The time windows were 09:00-10:00 (morning), 13:00-14:00 (afternoon), and 20:00-21:00 (evening). During the 7- day research period (14-20 October 2019), the 5 investigators collected parking data over the campus in a complete and non-overlapping manner.

To process the collected data, first, the videos were cropped frame by frame and matched to the GPS records according to the time recorded. Second, HyperLPR, which is an open-source license plate recognition library, was utilized to identify license plates in the frames. Third, considering the possible errors in plate recognition results, a criterion was proposed where license plates that differed by only one digit were regarded as identical. Fourth, duplicated records (i.e., records that had the same license plate and appeared at the same location at the same time) were eliminated. The process flow is shown in Figure 3. To protect the collected data, a unilateral encryption algorithm could be used to process the license plates. 


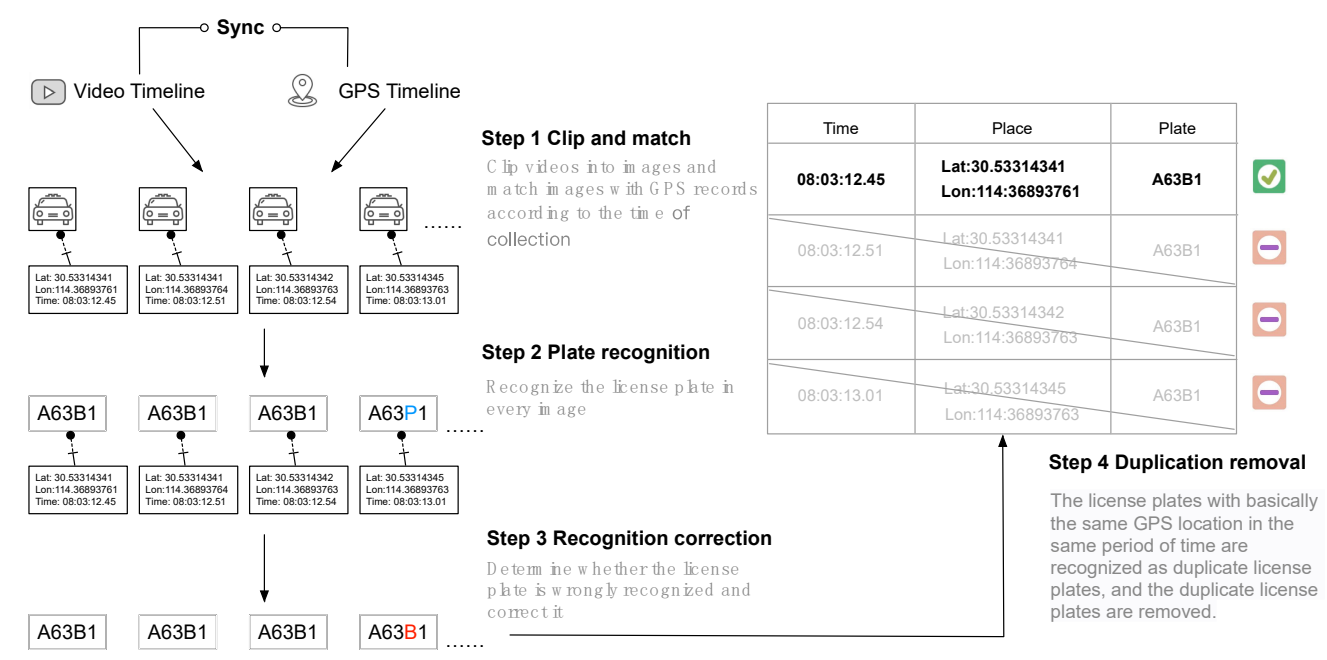

Figure 3. Parking data preprocess. First, videos collected by the self-designed app are clipped into frames to match the GPS records according to the collection time. Second, license plates in every frame are recognized. Then, rules are set to identify whether a certain license plate is erroneously recognized and correct the error. Finally, duplicated license plate records that have the same license plate, GPS location, and collection time are removed.

\subsubsection{Survey Data Preparation}

A questionnaire was designed to collect the attitudes of people in the Information Department Campus of Wuhan University towards the current parking situation, the influence of parking on their daily life, and their viewpoints on opening up the campus. The full version of the questionnaire can be found in Appendix A. The questionnaire was published online via https:/ /www.wjx.cn/ (accessed on 29 April 2020), and questionnaire responses were received as soon as they were submitted by participants. All the questions required that the participants choose one answer from a limited number of potential answers, and all the questions had to be answered. The questionnaire was distributed to the students and teachers via the communication platform of Wuhan University.

\subsection{Parking Zone Partition}

To conduct the parking analysis, and especially parking behavior analysis, it was necessary to integrate discrete parking spots into parking zones. Two approaches were introduced, as follows.

\subsubsection{Grid-Based Fine-Grained Parking Zones}

The campus was first partitioned into grids for fine-grid parking zone analysis (i.e., hot parking zone identification). A grid system covering the extent of the Information Department Campus of Wuhan University was created. The longitude and latitude span of each grid was 0.0001 degrees (about $11 \mathrm{~m}$ ). The area of the Information Department Campus of Wuhan University is about 645,200 square meters, and was covered by 5333 grids.

\subsubsection{Cluster-Based Coarse-Grained Parking Zones}

Parking spots were clustered by density-based spatial clustering of applications with noise (i.e., DBSCAN) [34] to obtain coarse-grained parking clusters, which were leveraged for all other analyses except hot parking zone identification. Given a set of points, DBSCAN groups together points that are closely packed together (points with many nearby neighbors), marking as outliers points that lie alone in low-density regions (whose nearest neighbors are too far away). It requires two arguments, i.e., MinPts, which defines the minimum number of points around the given point to form a group, and Eps, which refers to the minimum distance between points to form a group. The MinPts can be determined by the maximum scanning radius of natural neighbors as proposed in an algorithm [35]. To cal- 
culate Eps, the MinPts-th distances of all locations are first computed and sorted, and then slopes are calculated, where the value of the first slope that is above mean(slope)+standard deviation(slope) is assigned to Eps [36].

After that, the typical attribute of each cluster is determined considering the functions of buildings nearby, and clusters with the same attribute are integrated.

\subsection{Parking Analysis}

\subsubsection{Dynamic Traffic Volume Definition} flow.

Inflow and outflow of vehicles were proposed to present the dynamic volume of traffic

Inflow of vehicles is defined as

$$
I V=\frac{I F}{C N}
$$

where IF refers to the number of vehicles that are detected in the current time period but were not detected in the last time period, and $\mathrm{CN}$ refers to the number of vehicles in the current time period.

Outflow of vehicles is defined as

$$
O V=\frac{O F}{C N}
$$

where $O F$ refers to the number of vehicles that are detected in the current time period but will not be detected in the next time period, and $\mathrm{CN}$ refers to the number of vehicles in the current time period.

For example, the inflow of vehicles in the afternoon of 15 October 2020 was computed as the number of vehicles that were detected in the afternoon of 15 October 2020 but not detected in the morning of the same day, divided by the number of vehicles in the afternoon of that day; the outflow of vehicles in the afternoon of 15 October 2020 was computed as the number of vehicles that were detected in the afternoon but not detected in the evening of that day divided by the number of vehicles in the afternoon of that day.

\subsubsection{Spatiotemporal Parking Behavior Categorization}

Parking behavior was utilized to categorize the vehicles. Automatic clustering and rule-based matching were applied to classify all vehicles or some of the vehicles with specific parking characteristics, separately. For the convenience of explanation, we note from the results of Section 4.2 in advance that four parking zones, i.e., the teaching and working zone (shortened to "working zone"), the residence zone, the mixed zone, and the unclassified zone, were obtained by cluster-based partitioning and integration. To clarify, the unclassified zone consisted of parking spots that were considered to be "noise" parking spots; hence, the analysis mainly concentrated on the other three parking zones with meaningful parking spots.

Automatic clustering: Eighteen spatiotemporal parking features of vehicles were defined and extracted for behavior clustering, including parking zone selection ( 2 features), parking periods ( 2 features), parking frequency in different zones ( 8 features), and parking frequency at different times ( 6 features) during weekdays or weekends. The explanations of the 18 features as well as examples of feature coding are listed in Table 1. 
Table 1. Description of 18 spatiotemporal parking features and coding used for the analysis.

\begin{tabular}{ccc}
\hline Features & Explanation of Features & Feature Coding \\
$\begin{array}{c}\text { Recorded in the format of tuples. } \\
\text { Pumbers in the tuple refer to the } \\
\text { weekdays/weekends } \\
\text { occurrence of vehicle parking in the } \\
\text { four parking zones: working zone, } \\
\text { residence zone, mixed zone, and } \\
\text { unclassified zone. }\end{array}$ & $(6,11,0,0)$ \\
\hline $\begin{array}{c}\text { Parking periods on the } \\
\text { weekdays/weekends }\end{array}$ & $\begin{array}{c}\text { Recorded in the format of tuples. } \\
\text { occurrence of vehicle parking in the } \\
\text { three time periods: morning, } \\
\text { afternoon, and evening. }\end{array}$ & $(2,2,2)$ \\
\hline $\begin{array}{c}\text { Parking frequency in working } \\
\text { zone/residence zone/mixed } \\
\text { zone/unclassified zone on } \\
\text { weekdays/weekends }\end{array}$ & Recorded in integer format & \\
\hline $\begin{array}{c}\text { Parking frequency in the } \\
\text { morning/afternoon/evening } \\
\text { of weekdays/weekends }\end{array}$ & Recorded in integer format & \\
\hline
\end{tabular}

To cluster vehicles according to the similarity of their spatiotemporal parking behavior, the MST-DCVI clustering algorithm [35] was applied. This algorithm builds and prunes the minimum spanning tree according to the distance between tree nodes (i.e., vehicles) to obtain the clustering results. To compute the distance between tree nodes, the Cosine Distance was utilized for the four features, including parking zone on the weekdays/weekends and parking periods on the weekdays/weekends. For the other 14 features, the distance between two nodes was computed by the Euclidean Distance. The distance range of 4 features including the parking zone on the weekdays/weekends and parking periods on the weekdays/weekends was converted to [0,3], while the distance range of other features was converted to $[0,1]$, because the preference for parking time and parking zone was considered to matter more than parking frequency. The distances between two nodes that integrated all 18 features were computed by the Euclidean Distance.

Given the example of license plate $1((6,11,0,0),(1,5,0,0), 5,5,4,2,2,2,6,8,0,0,1,5,0$, $0,(5,5,4),(2,2,2))$ and license plate $2((0,0,15,0),(0,0,4,0), 5,5,5,2,1,1,0,0,15,0,0,0,4,0$, $(5,5,5),(2,1,1))$, the cosine distance between the two records for the feature of parking zone on the weekdays is:

$$
C D((6,11,0,0),(0,0,15,0))=\frac{6 \times 0+11 \times 0+0 \times 15+0 \times 0}{\sqrt{6^{2}+11^{2}+0^{2}+0^{2}} \times \sqrt{0^{2}+0^{2}+15^{2}+0^{2}}}
$$

The Euclidean distance between the two records for the feature of parking frequency in the evening of weekdays is:

$$
E D(4,5)=\sqrt{(4-5)^{2}}
$$


Additionally, the distance between the two records is computed as:

$$
\begin{aligned}
\text { distance }_{1,2}= & E D O((C D((6,11,0,0),(0,0,15,0))-1 \times 3), \\
& (C D((1,5,0,0),(0,0,4,0)-1 \times 3), \quad E D(5,5) \div 5, \\
& E D(5,5) \div 5, \quad E D(4,5) \div 5, \quad E D(2,2) \div 2, \\
& E D(2,1) \div 2, \quad E D(2,1) \div 2, \quad E D(6,0) \div 15, \\
& E D(8,0) \div 15, \quad E D(0,15) \div 15, \quad E D(0,0) \div 15, \\
& E D(1,0) \div 6, \quad E D(5,0) \div 6, \quad E D(0,4) \div 6, \\
& E D(0,0) \div 6, \quad(C D((5,5,4),(5,5,5))-1) \times 3), \\
& (C D((2,2,2),(2,1,1))-1) \times 3)=4.602
\end{aligned}
$$

where

$$
E D O(x, y, z)=\sqrt{n_{1}{ }^{2}+n_{2}{ }^{2}+\ldots+n_{i}{ }^{2}+\ldots+n_{18}{ }^{2}}, \quad i=1,2,3, \ldots, 18
$$

For two vehicles, the smaller the distance between them, the more likely that they were classified into the same category.

Rule-based matching: Moreover, vehicles with certain semantic patterns were defined. The semantic pattern rules, listed in Table 2, were leveraged to filter vehicles of specific patterns. Specifically, "Vehicles for commuting within campus" referred to the typical vehicles owned by faculty and staff who lived on campus and that are driven to commute within the campus between the dormitory the owner lives in and the building she works in; "Zombie vehicles" were vehicles that never move; "Vehicles staying over" implied vehicles of this category that were present mainly at night but seldom in the daytime (i.e., vehicles that came to park at night during the week at least 2.5 times as often as they parked during the day); vehicles that came to the campus only on weekday afternoons were "Vehicles parked on weekday afternoons".

Table 2. Semantic pattern rules for parking behavior.

\begin{tabular}{ccc}
\hline Name of Patterns & $\begin{array}{c}\text { The Zone the Vehicle Is } \\
\text { Parked in }\end{array}$ & The Frequency They Park \\
\hline $\begin{array}{c}\text { Vehicles for commuting } \\
\text { within campus }\end{array}$ & $\begin{array}{c}\text { Working zone or residence } \\
\text { zone }\end{array}$ & Weekdays $\geq 9$ Weekends $\geq 2$ \\
\hline Zombie vehicles & $\begin{array}{c}\text { No matter which zone they } \\
\text { are parked in, they are only } \\
\text { parked in a specific zone }\end{array}$ & Weekdays $\geq 15$ Weekends $\geq 6$ \\
\hline Vehicles staying over & Any zone & $\begin{array}{c}\text { Weekdays (morning and } \\
\text { afternoon) and weekends } \\
\text { (morning and afternoon) } \leq 2 \\
\text { Weekdays (evening) } \geq 4\end{array}$ \\
Wehicles parked on weekday \\
afternoons
\end{tabular}

\section{Results}

A total of 3788 different license plates were identified during 14-20 October 2020. Of the different time periods in one day, it can be seen from Figure 4 that the frequency of parking reached its maximum in the afternoon of that day, and on Thursday afternoon the frequency of parking was the highest (1404) among all seven afternoons. In addition, there were more instances of parking (more than 150) in the morning than in the evening on weekdays, but this trend was reversed on weekends. Finally, the campus had more parking during the weekdays than weekends, no matter which time period was examined. Specifically, there were 200 more parked vehicles in the morning (or afternoon) on weekdays 
than on weekends, while the difference in the number of parked vehicles varied only slightly in the evening.

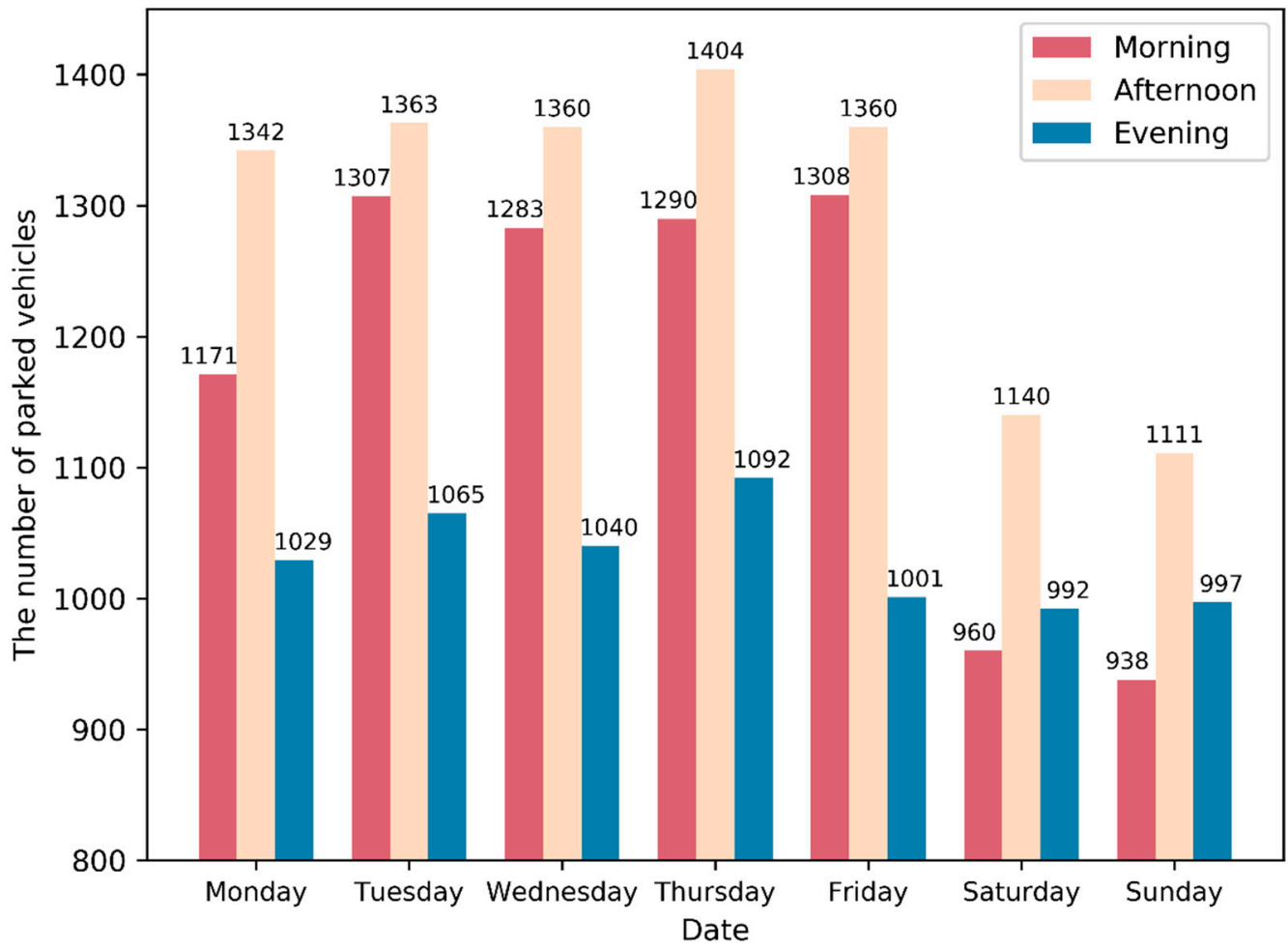

Figure 4. The number of parked vehicles in the morning, afternoon, and evening on each day of the week.

\subsection{Hot Parking Zone}

The hot parking zone referred to the zone of a busy parking situation in a specific time period and was examined in the grid-based partition. By integrating the parking data in the morning, afternoon, and evening for all days in the week and counting the vehicles located in each grid, hot parking spots during different time periods could be identified. From Figure 5, there were two regions where the parking spots were "hot" all day, i.e., (A) Teaching Building 1 and (B) Deren Square. In the morning and afternoon, the parking spots around (C) the basketball playground, and (D) the Students' Activity Center were rather hot, but there was less parking demand in the evening. The parking spots near (E) Students' Canteen 2 and (F) Experimental Building became hot in the afternoon, and there were still many vehicles parking there in the evening. Some parking spots in the residential area $(G)$ were hot in the afternoon and evening, too.

\subsection{Clustered Parking Zones}

From Section 3.2.2, 27 clusters were obtained and were further integrated into four parking zones, including the working zone, the residence zone, the mixed zone, and the unclassified zone, as presented in Figure 6. Specifically, the working zone included clusters closed to teaching and office buildings; the clusters of the residence zone were located near residential buildings for faculty and staff; buildings with various functions were next to the parking spaces in the mixed zone; and unclassified zone included all parking spots that could be classified into any cluster in the clustering process. 
(a) Morning

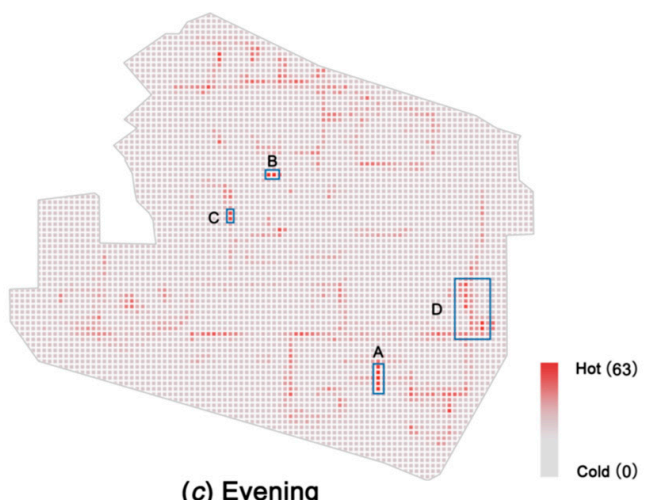

(c) Evening

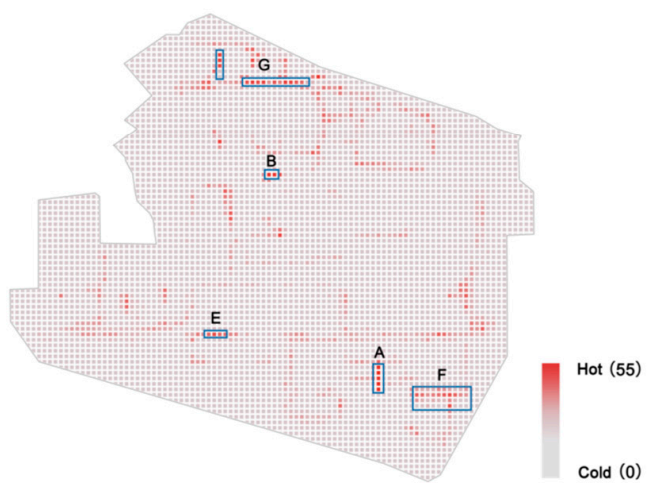

(b) Afternoon

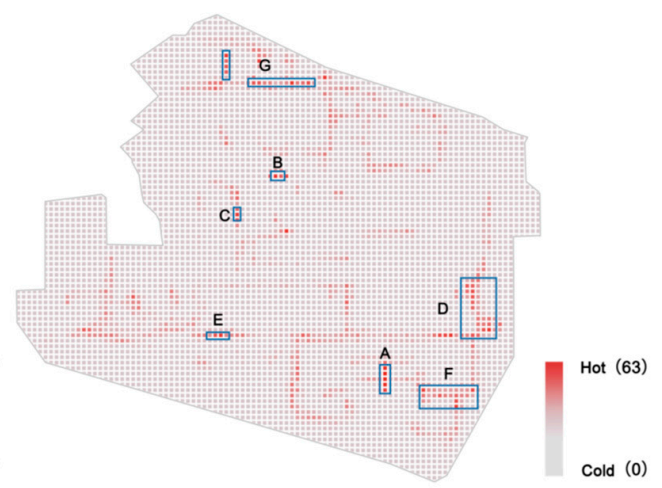

$\Lambda^{\text {North }}$

Figure 5. Hot parking zones in three time periods, including (a) the morning, (b) the afternoon and (c) the evening. The redder the grids, the more parking they accommodate. The grids circled by the blue rectangles represent the regions of highest parking demand. The source of the map is OpenStreetMap.

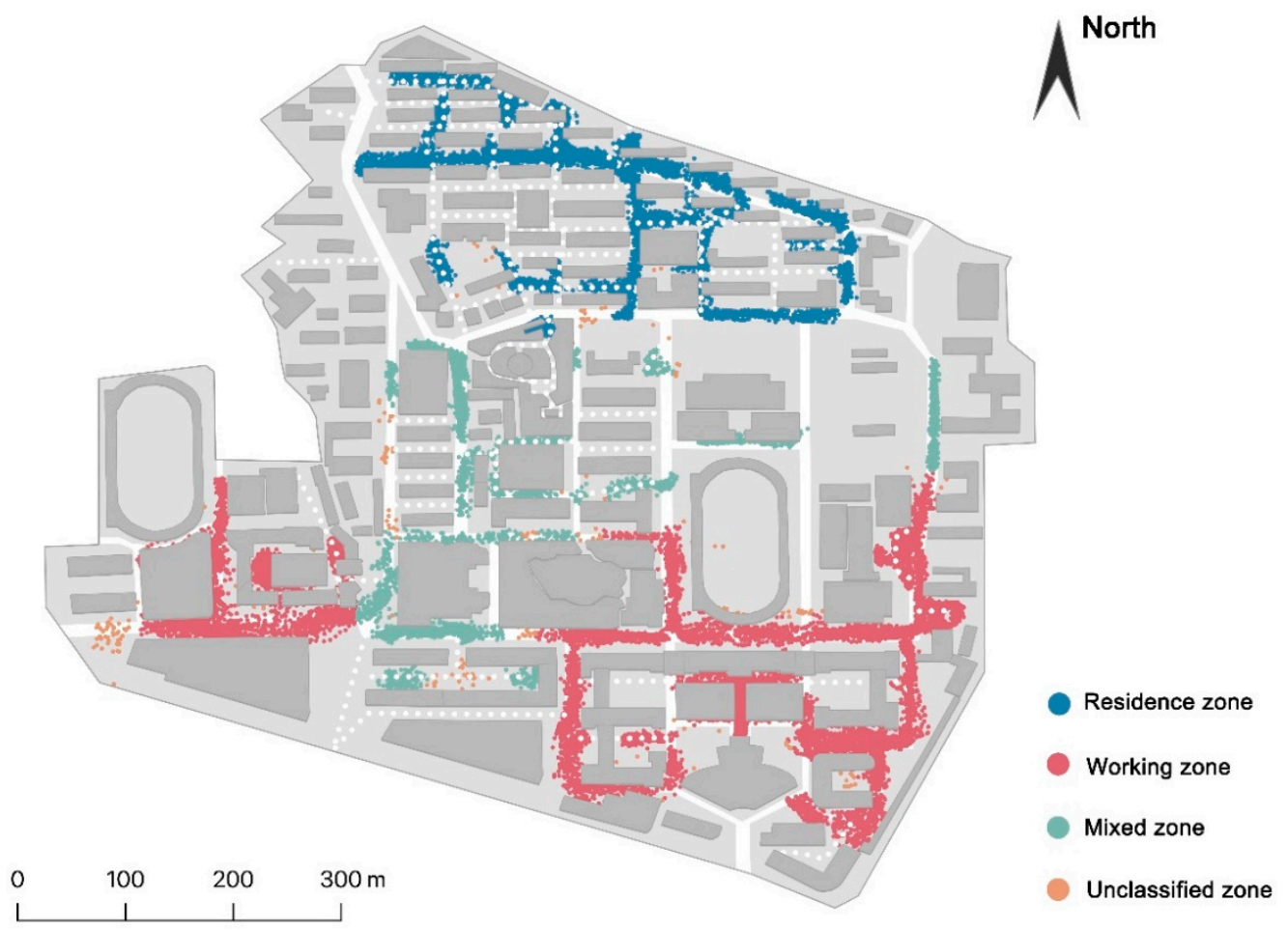

Figure 6. The distribution of four parking zones in the Information Department campus of Wuhan University. The source of the map is OpenStreetMap. 


\subsection{Dynamic Parking Demand}

The number of parked vehicles in the residence zone, the working zone, and the mixed zone during different time periods was examined. As presented in Figure 7, the parking demand in the working zone was the highest among the three zones, while that in the mixed zone was the lowest. Four times as many cars could be parked in the working zone as in the mixed zone. Specifically, during the weekdays, parking spots in the working zone and the mixed zone were more popular in the afternoon than in the morning, and were least popular in the evening, whereas parking spots in the residence zone became increasingly popular from morning to evening. On weekends, parking demand decreased in the working zone and the mixed zone in the daytime (especially in the morning) while changing little in the residence zone. Parking demand increased in all three zones during weekend evenings. No matter which time period was specified, parking demand in the mixed zone was lowest among the three parking zones.

$\bigcirc$ Morning $\bigcirc$ Afternoon $\bigcirc$ Evening

(a) Residence zone

(b) Working zone

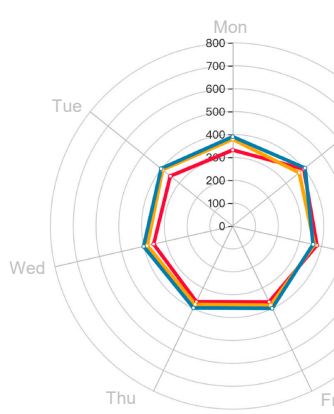

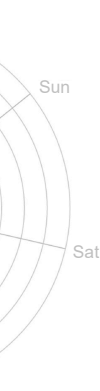

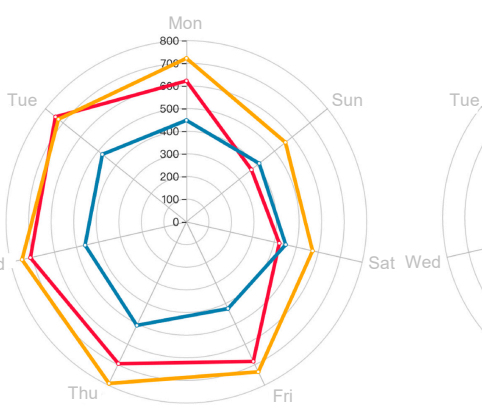

(c) Mixed zone

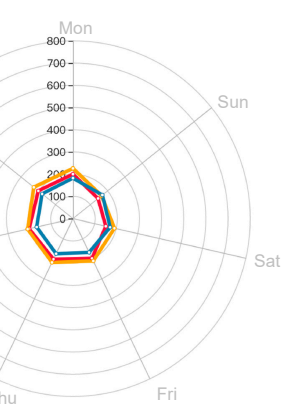

Figure 7. The number of parked vehicles in (a) the residence zone, (b) the working zone, and (c) the mixed zone in the morning, afternoon and evening on every day of the week. Each colored line in the subfigure represents a time period, i.e., the morning (red line), the afternoon (orange line), or the evening (blue line). The circles stand for a week, which is equally divided into 7 parts representing Monday to Sunday.

The inflow and outflow of vehicles in the three parking zones (the residence zone, the working zone, and the mixed zone) and the ratio of inflow to outflow were computed as shown in Figure 8. RZ, WZ, and MZ referred to the residence zone, the working zone and the mixed zone, respectively. Morning, afternoon, and evening in the inflow heatmap (or the outflow heatmap or the inflow/outflow ratio heatmap) indicated the inflow (or outflow or the ratio of inflow to outflow) of vehicles in the morning, afternoon, and evening. The $\mathrm{N} / \mathrm{A}$ in the inflow heatmap (and the outflow heatmap) was due to the lack of data for the day immediately preceding (13 October 2019) and following (21 October 2019) the research period.

As can be seen from Figure $8 \mathrm{a}$, first, on weekdays the inflow of vehicles into both the working zone and the mixed zone was concentrated in the morning (2nd 3rd column and 1st 5 th row) while on weekends it concentrated in the afternoon (8th 9th column and 6th 7th row); second, in the evenings of all days of the week (7th 9 th column and 1st 7 th row), the overall inflow was high for the parking lots in the mixed zone, accounting for most of the parking. Considering the outflow of vehicles, first, many vehicles parked in the working zone and the mixed zone (5th 6th column and 1st $\sim 7$ th row) in the afternoon would leave before evening, and on weekdays they accounted for more than half of the vehicles parked in the afternoon. Second, in every time period, the percentage of parked vehicles departing from the residence zone was the smallest (1st, 4th and 7th column and 1st $\sim 7$ th row). Moreover, when the parked vehicles in the morning (1st 3rd column and 1st $\sim 7$ th row), afternoon (4th $\sim 6$ th column and 1st 7 th row), and evening (7th $\sim 9$ th column 
and 1st $\sim$ th row) are compared, vehicles parked in the morning accounted for the smallest percentage of departures.

As for the inflow and outflow of vehicles, it can be seen from Figure $8 \mathrm{c}$ that, in the evening, the inflow and outflow in the mixed zone (9th column and 1st 7th row) were almost equal (i.e., around 1.0). The ratio of inflow to outflow on Friday evening was higher compared to that in the evening on other weekdays (9th column and 1st $\sim 5$ th row).
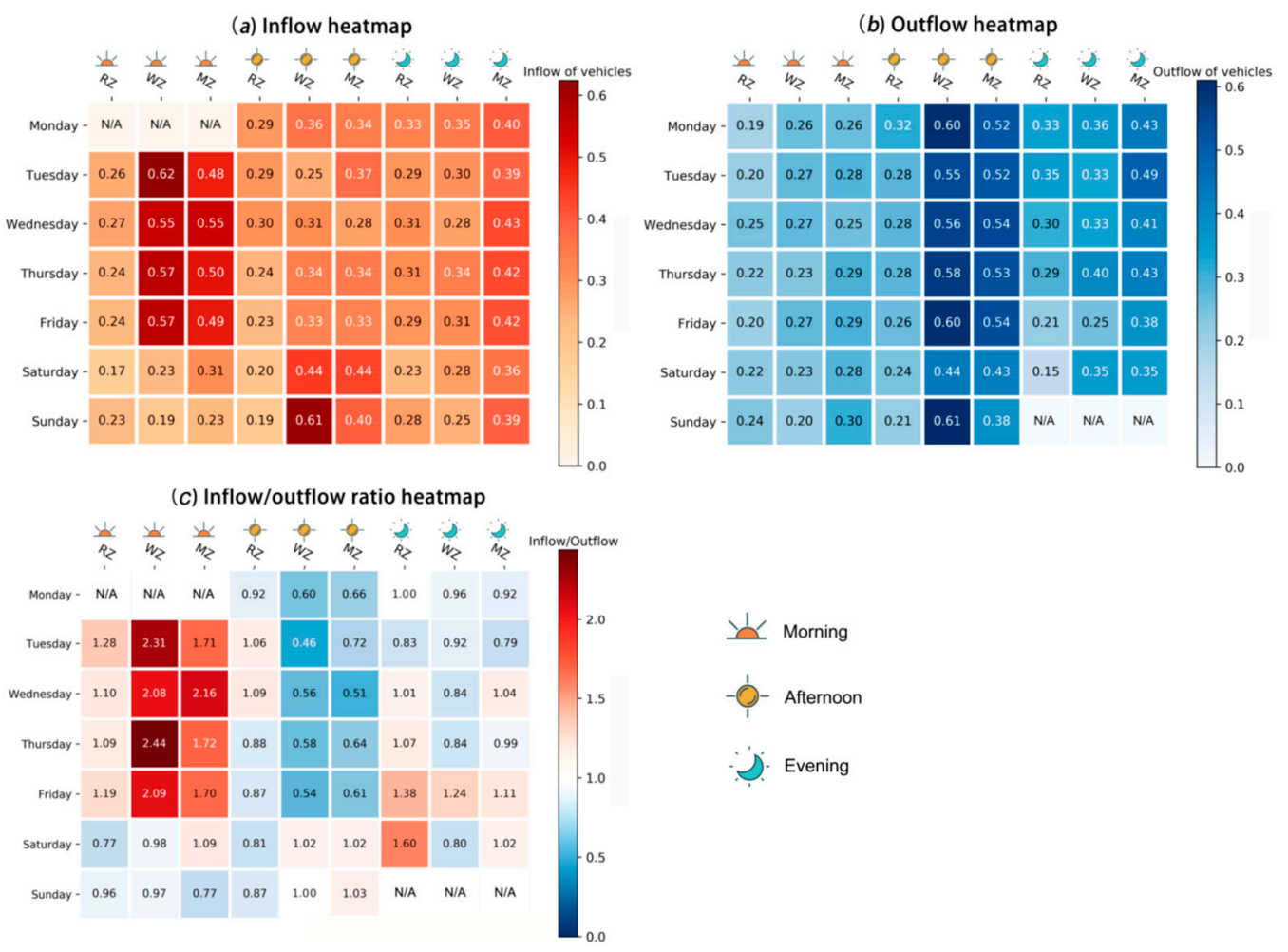

Figure 8. (a) Inflow heatmap, (b) outflow heatmap and (c) inflow/outflow ratio heatmap. Inflow and outflow are both in the form of proportion. Inflow of vehicles is computed using Equation (1) and outflow of vehicles is computed using equation (2). In the subfigure (a), the darker the color, the more cars come to park; in subfigure (b), the darker the color, the more cars leave. In subfigure (c), red means there are more cars coming to park than leaving, while blue means there are more cars leaving. RZ, WZ, and MZ are the abbreviations for residence zone, working zone, and mixed zone.

\subsection{Vehicle Categorization}

Clusters were obtained from the MST-DCVI clustering algorithm based on vehicles' spatiotemporal parking behavior (Section 3.3.2). By merging clusters with similar behavioral characteristics, 4 categories were obtained, as follows:

- Vehicles in Category 1 occasionally come to school on weekdays or on weekends, but do not appear both on weekdays and weekends. These vehicles do not have a preference for parking zone or parking time. Thus, they may come in any of the time periods and park in any of the four parking zones. Vehicles in this category is named visiting vehicles.

- Vehicles in Category 2 are believed to be the vehicles of faculty and administrative staff living off campus because these vehicles usually appear in the daytime and are exclusively parked in the working zone. On weekdays they all appear in a high frequency. On weekends, some of them still come to school often.

- Vehicles in Category 3 are assumed to be the vehicles of faculty and administrative staff living on campus because they are mostly parked in the residence zone with high frequency. 
- Vehicles in Category 4 park mainly in the mixed zone, and the majority of them are parked frequently during a week. They are thought to be vehicles of off-campus personnel.

The totals of visiting vehicles, vehicles of faculty and administrative staff living off campus, vehicles of faculty and administrative staff living on campus, and vehicles of offcampus personnel were $888,1907,772$, and 221, respectively. The proportions of vehicles in each category were $23.4 \%, 50.3 \%, 20.4 \%$, and $5.8 \%$, respectively. Figure 9 demonstrates that visiting vehicles and vehicles of off-campus personnel made up more than $1 / 4$ of vehicles parked on the campus.

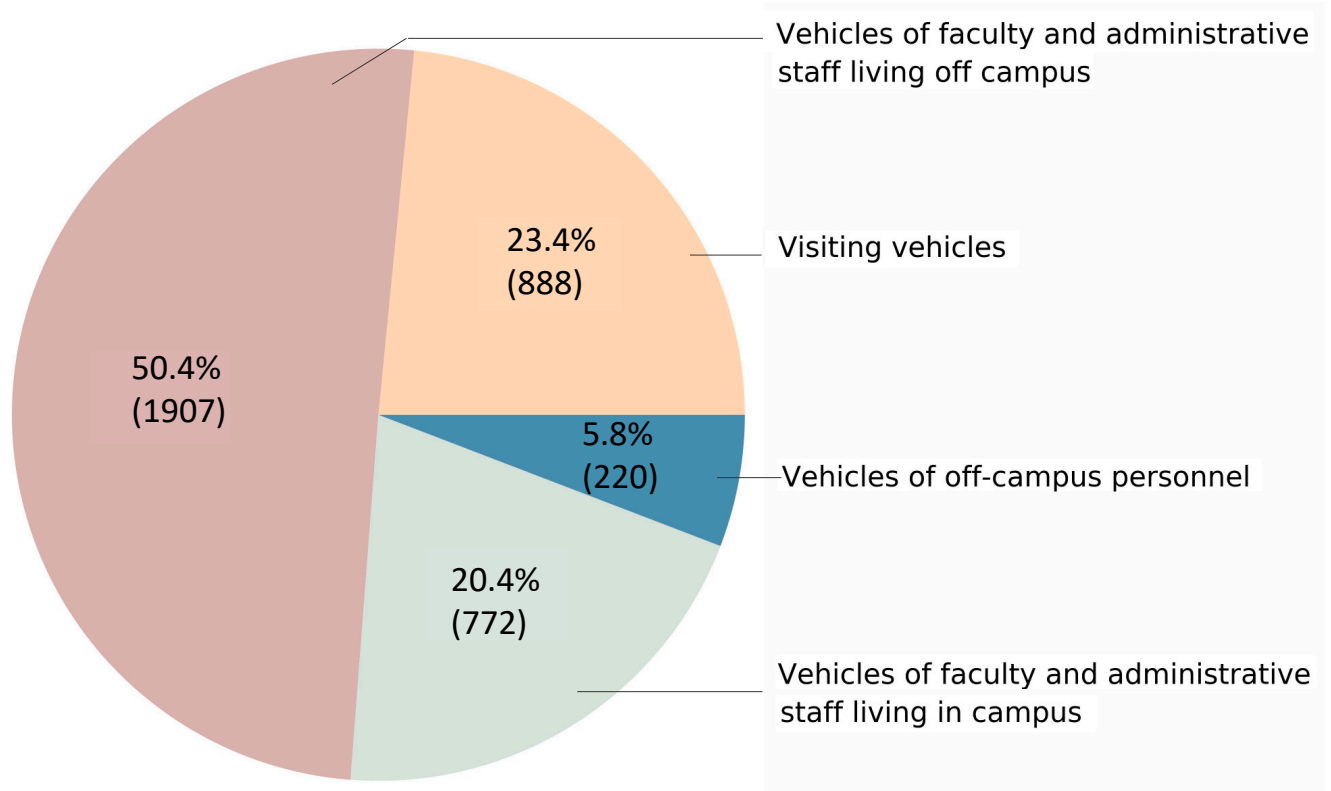

Figure 9. Percentage of vehicles in the four categories.

With the spatiotemporal characteristics of certain semantic patterns presented in Section 3.3.2, vehicles of each pattern were identified and counted, as displayed in Table 3. Furthermore, parking calendars of these patterns are introduced in Figure 10.

As a result, there were 58 typical vehicles of the V-CC pattern, and these vehicles were mostly parked in the residence zone, especially in the evening and on the weekends. $\mathrm{V}-\mathrm{CC}$ pattern vehicles would also park in the work zone and preferred the daytime on weekdays. Most vehicles of the V-Waft pattern parked mainly in the working zone; some parked in the mixed zone and a few parked in the residence zone, but a minority of them occasionally parked in the unclassified zone. In addition, the inner circles in Figure 10b show that although vehicles of V-WAft added up to 447, only a small number of them appeared on the same day, which indicates that they came to campus in a low frequency. Moreover, the 12 vehicles of V-Stay mostly appeared in the residence zone and the work zone, while some would park in the mixed zone. As for vehicles of V-Zomb, there were 153, of which $43.14 \%$ were parked in residence zone, $39.21 \%$ in the working zone, and $17.65 \%$ in the mixed zone.

Table 3. The number of vehicles in each of the interesting patterns.

\begin{tabular}{cc}
\hline Name of Patterns & The Number of Vehicles \\
\hline Vehicles for commuting within campus (V-CC) & 58 \\
Zombie vehicles (V-Zomb) & 153 \\
Vehicles staying over (V-Stay) & 12 \\
Vehicles parked on weekday afternoons (V-WAft) & 447 \\
\hline
\end{tabular}




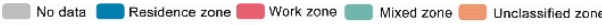

The number and size represent the quantity of vehicles

(a) Vehicles for commuting within campus

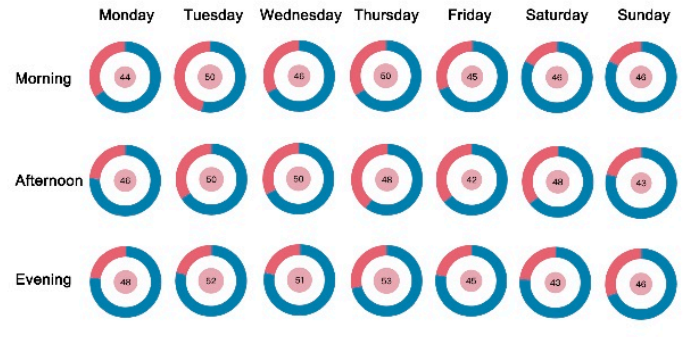

(c) Vehicles stay over

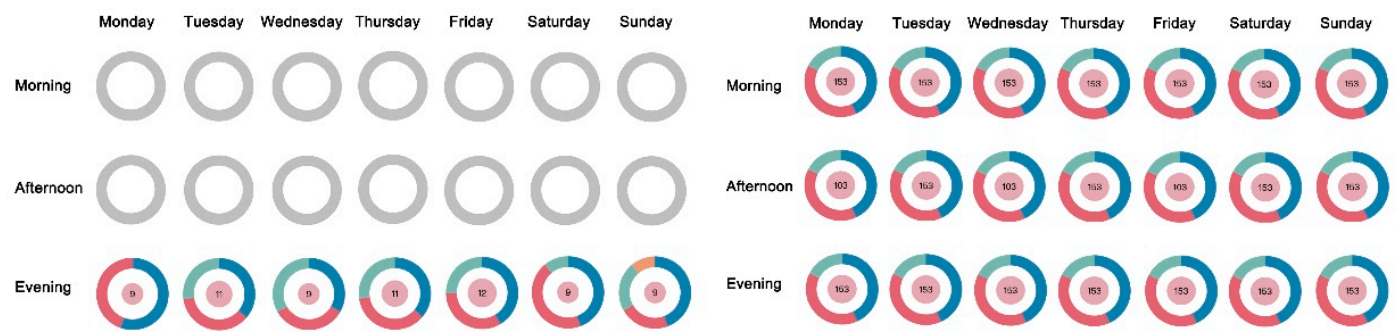

(b) Vehicles parked on weekday afternoons

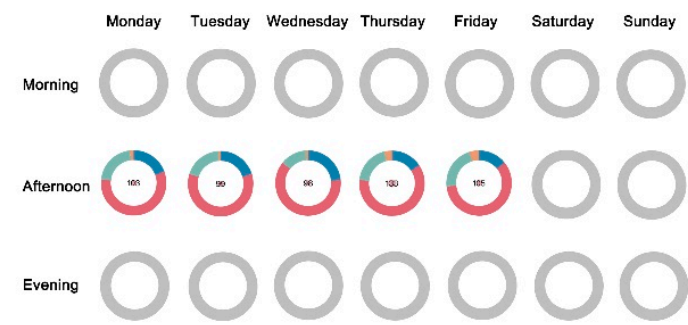

(d) Zombie vehicles

Figure 10. Parking calendars of vehicles with certain semantic patterns. (a) Vehicles for commuting within campus; (b) vehicles parked on weekday afternoons; (c) vehicles staying over; (d) zombie vehicles. The outer donuts represent the proportion of vehicles that belong to a specific pattern (e.g., zombie vehicles) parking in each of the four parking zones. The four colors in the outer donuts refer to the four parking zones. The number and size of inner circles imply the quantity of vehicles of a specific pattern appearing in the specific period. For example, there are 447 vehicles belonging to the category "vehicles parked on weekday afternoons", but only 103 of them appear in the Monday afternoon time period.

\subsection{Perceptions of Parking Situation}

In total, 141 completed questionnaires were returned. Of the respondent total, 133 who filled out the questionnaires were at Wuhan University in 2019, whereas the remaining 8 respondents were at other universities. The completed questionnaires from the 133 Wuhan University respondents were used for further analysis. Of those, 61 were students and 72 were faculty or staff. A total of 118 spent most time on the Information Department Campus, accounting for $88.7 \%$ of the sample size. The ratio of respondents that had/did not have private vehicles was around 1:1.

Regarding the current parking situation on the Information Department Campus, $70.7 \%$ of the 133 respondents thought that the parking situation was chaotic, and $27.8 \%$ commented that the parking situation was extremely chaotic. More than half $(60.2 \%)$ believed that Information Department Campus parking resources were overused, and that there were too many parked vehicles. A $30.8 \%$ share of the respondents felt that the parking resources were slightly overused, and that only a few too many vehicles parked there. Only $9.0 \%$ of respondents believed that the parking situation was moderate on the Information Department Campus. No one felt that the Information Department Campus could provide parking spaces to accommodate more vehicles.

As for the influence of the parking situation on daily life, $76.7 \%$ of the respondents complained about it, and $26.3 \%$ claimed that they suffered from the parking situation. A $92.5 \%$ share of all respondents expressed hope that the university would strengthen its management of the parking situation on the Information Department Campus.

When asked whether they approved the idea of socializing the campus roads and parking spaces, $50.4 \%$ disapproved, whereas $41.4 \%$ approved and the remaining respondents indicated that they did not care. It is worth mentioning that the ratio of students who approved and disapproved was 1:1, whereas faculty and staff expressed the opposing views in a ratio of 1:1.4. 


\section{Discussion and Conclusions}

In this study, it was shown that using low-budget data collection methods to conduct scientific research and perform in-depth and detailed analyses could help understand the current parking situation. Semantic extraction of the spatiotemporal distribution of vehicles allowed us to explore the typical parking patterns and their consequent management. The following discussion reflects on the vehicle parking problem in the study area (and in other danweis) based on the above results of our study.

\subsection{Short Supply against High Demand}

There are 409, 296, and 116 above-ground parking spots in the working zone, residence zone, and mixed zone, respectively. However, the minimum numbers of parking spots to meet actual demand in the three zones during weekdays were 622,332 , and 168 . Therefore, even when parking demand is at its lowest level, the parking facilities in each parking zone can hardly accommodate it. This imbalance between parking resources supply and demand also exists on other campuses $[14,24,29,30]$, whether in China or abroad, which underlines the urgency of managing campus parking problems.

Observations on the Information Department Campus of Wuhan University indicated that many vehicles parked in open spaces or on the roadside, where there were no standard parking spots, due to insufficient on-campus parking space. This also implied that unless practical management steps are taken, the campus has a poor likelihood of functioning as part of the city's public transportation system or providing parking services for off-campus vehicles.

For other danweis, systematic parking analysis could also help with identifying the reasons for certain parking phenomena and conducting feasibility trials before policy implementation.

\subsection{Vulnerabilities in Parking Resource Management}

From the results above, we identified at least two vulnerabilities in parking resource management.

First is the regulation of resource utilization. There were 153 zombie vehicles, making up more than $4 \%$ of vehicles on campus. Zombie vehicles occupy parking spaces for a long time, and most are parked in either the residence zone or the working zone, which have limited parking resources. Zombie vehicles exist for many possible reasons. First, the owner of a zombie vehicle does not leave campus often or prefers to use public transit. Therefore, the vehicle is used only for special circumstances. Second, the owner of the zombie vehicle has other vehicles that they often drive. Third, the zombie vehicle is scrapped, and its owner has abandoned it. No matter the reason, action should be taken to free up the limited parking resources occupied by zombie vehicles. However, on further investigation, we found that no corresponding measures had been drawn up.

Moreover, due to limited parking space, some people set private parking locks on public parking spots to reserve them as their own parking spots. This makes an already insufficient number of parking spaces even more inadequate.

Second is the supervision of established policies. Though the campus only allows vehicles of off-campus personnel to park temporarily, some still park longer than is permitted. A total of 220 vehicles used by off-campus personnel were identified, and there were 12 vehicles that stayed overnight. This situation with vehicles of off-campus personnel frequently parking on the campus may have something to do with the parking fee [37]. On campus, teachers and campus administrators pay only a nominal parking fee of $¥ 360$ a year, whereas most of the surrounding commercial parking lots charge $¥ 3 / h, ¥ 5 / h$ or $¥ 8 / h$, and $¥ 30 \sim 40$ for overnight parking. This gives off-campus car owners a huge incentive to take advantage of the extremely low parking fees by working with car-less on-campus employees and registering their vehicles under the employees' names in the university's vehicle management system. 
We believe that the vulnerabilities in parking management are not limited solely to the studied campus. Other Chinese danweis, especially those that have excessively large areas for real-time monitoring, should occasionally adopt similar analyses to check for deficiencies in management. Vulnerabilities in management can be identified through in-depth and detailed analysis.

\subsection{Unnecessary Vehicle Usage}

Based on our results, more than $7 \%$ of vehicles belonging to faculty and staff living on campus were used to commute within campus where the distance between the residence zone and the working zone is less than 1 mile. These vehicles were parked in the residence zone mostly, but also appeared in the working zone. Fifty-eight vehicles commuted within campus, and Tuesday was the peak. There might be many reasons to explain the commuting within campus using private cars, such as a lack of time to use other transportation modes. However, using cars to commute within a 1-mile radius is a waste of both campus roads and parking resources. Using policies to encourage active commuting could not only save $7 \%$ of road and parking resources, but also promote the health of employees [38]. Additionally, from the perspectives of the entire city public transportation system as well as energy conservation and emission reductions, it is meaningful to encourage active commuting.

\subsection{From Parking Behavior to Life State}

The parking behavior of car owners reflects their life situation and schedule.

Among car owners, on weekends, fewer come to school, and people living on campus are more likely to stay at home through the day, especially in the morning. However, the number of parked vehicles on campus in the evenings on weekends is similar to that on weekdays. This fact might reflect the pressures on Chinese scholars. During the daytime on weekends, they focus on handling pressures from family and life, and in the evening, they get back to work [39]. Based on the observation that every afternoon is the peak for parking, i.e., there are more people on campus in the afternoon than in the morning (or evening), it can be inferred that some faculty, staff, and students living off campus come to work and study just before lunchtime.

\subsection{Recommended Parking Management}

Transportation demand management (TDM) is a widely adopted strategy of parking management. For example, it includes providing transit services [40,41], compressing the workweek [42], promoting taxi-sharing [14], and adjusting parking fees [12]. Recommendations with reference to TDM strategies have been thought through according to the results and the characteristics of danweis:

1. As the government calls for the use of underground space when building parking lots, we suggest that a central parking lot with at least 300 parking spaces could be built under the playground in the mixed zone. The new parking spots would only allow entry if the names on the user's driving license and campus ID are the same. With the employee information database, intelligent gate control could check if the requester is an employee of the danwei and compare whether the driving license and the campus ID presented by the requester are consistent.

2. Lei and Ouyang [43] cite the effectiveness of dynamic parking fee strategies in improving urban parking. We suggest a dynamic fee system be used for all on-campus parking spaces. By installing parking locks with an automatic billing system on the parking spots, dynamically setting parking fees would be a practical approach.

3. According to [14], dynamic taxi-sharing would be helpful We suggest that more flexible electric on-campus taxis and excursion buses be launched, in addition to existing campus transit.

4. Sensors should be placed on parking spots to monitor if they are vacant [44-46] and used properly. 
5. In line with the proposal to reduce the use of private cars, we suggest that for the first vehicle owned by university employees, a monetized parking allowance should be issued, while for the second vehicle, no allowance should be given. The registration records for employees' vehicles could be used for reference.

6. To reduce on-campus commuting, commuters living on campus who show up at work without a vehicle for a month could be awarded a bonus, as proposed in [47]. The parking lock mentioned in Recommendation 2 could record the campus ID that has paid for the parking fee. Thus, employees who do not drive a car could be identified.

7. In the implementation of "opening up microcirculation", campus roads are shared with city transportation. However, the danwei should use economic approaches to restrict off-campus vehicles from occupying on-campus parking.

The first three recommendations are strongly recommended, and the 4th 6th recommendations are optional but should be implemented if resources permit. The final recommendation is about how to respond to the current situation and should be considered seriously.

\subsection{Transferability of the Approach}

Though the experiment in this work was conducted on the Information Department Campus of Wuhan University, we believe in the transferability of our approach. First, the approach could be generalized to other Chinese danweis, as the data collection method, the parking zone partition method, and the parking analysis method pose no constraints on the targets of study. Second, the approach could be generalized to other scenarios other than danweis as long as the study target has a clear boundary and the buildings inside have certain functions. For example, the approach is suitable for almost all campuses, but it may fail for a park without boundaries.

\subsection{Conclusions}

In the informatization construction of a city, a danwei is often regarded as the smallest unit with one unique postal address. However, for historical reasons, the geographic space and population contained in a single danwei can be enormous. The isolated traffic system creates a huge challenge for the informatization construction of danweis.

In this paper, the parking situation on the Information Department Campus of Wuhan University was studied as an example to explore both a systematic approach to analyze the parking situation in danweis and a scientific strategy for a danwei/university campus to respond to the municipal call for "opening up the traffic microcirculation". We presented a new method of data collection and a novel framework for parking situation analysis. Practical policy recommendations were proposed based on the analysis.

Specifically, the mobile-based method for parking data collection, which allows for efficient, flexible, and low-cost data collection of spatial and temporal characteristics of vehicle parking in enclosed areas, is a convenient alternative to the manual approach [29] and a low-budget alternative to the intelligent parking monitoring system, as implemented in [26]. Moreover, the parking pattern analysis method, containing the joint analysis of vehicle parking patterns and parking space usage in the analytical framework, was systematically developed and well-generalized. It provides a practical way to study the current parking situation in Chinese danweis and may serve to better understand the parking needs within a danwei. What is more, recommendations were suggested based on TDM, which enriches the scenarios of TDM and illustrates its effectiveness. Last but not least, though this research was carried out on a campus of Wuhan University, it may serve as a representative example of how danweis in a Chinese city, and even organizations in other countries, should respond to their municipality's call: using modern technology to conduct scientific and creative research, perform in-depth and detailed analysis, and synthesize localized policy recommendations. 


\subsection{Limitations and Future Work}

Although this research provided a way to systematically analyze the parking status of Chinese danweis, it has to be pointed out that there were still some limitations. First, when there are many parking lots and paths in a danwei, collecting relatively comprehensive parking data inevitably demands rather heavy manpower. Second, the time windows demand extra field trials to determine, and they may change based on the types of danweis and work schedules in different seasons. Third, the accuracy of license plate recognition could be further improved with better license plate recognition libraries. Fourth, the clustering result of parking zones presented in Figure 6 might be improved. Specifically, the four parking zones presented in Figure 6 were integrated from 27 clusters obtained with the DBSCAN clustering algorithm, in which the hyperparameters were determined with reference to the literature. We also sought to set the hyperparameters based on experiences, but the clustering results did not improve significantly. In the integration process, the typical attribute of each cluster was determined considering the functions of buildings nearby, and clusters with the same attribute were integrated. We are confident in the reasonability of our result because the current version is accepted by the authors who have lived on the Information Department Campus of Wuhan University, but we also think that the clustering result could be improved.

In the future, parking patterns in danweis over a larger time horizon are worth exploring, such as in terms of a yearly variation, which may provide both the basic knowledge for more detailed management and understanding of human life patterns. Furthermore, given that the sharing of bicycles is widely adopted in danweis and their placement is usually chaotic, it would be worthwhile to analyze and propose management suggestions for bike sharing.

Author Contributions: Conceptualization, Teng Fei and Wenyuan Kong; methodology, Wenyuan Kong and Qian $\mathrm{Xu}$; software, Wenyuan Kong; validation, Wenyuan Kong and Teng Fei; formal analysis, Wenyuan Kong; investigation, Wenyuan Kong, Caiying Liao and Jiabei Wang; resources, Wenyuan Kong, Caiying Liao and Jiabei Wang; data curation, Wenyuan Kong; writing-original draft preparation, Kong, W. and Teng Fei; writing—review and editing, Wenyuan Kong and Teng Fei; visualization, Wenyuan Kong; supervision, Teng Fei; project administration, Wenyuan Kong funding acquisition, Teng Fei. All authors have read and agreed to the published version of the manuscript.

Funding: his work was supported by the [the National Key Research and Development Plan of China] under Grant [2017YFB0503601], and Wuhan University “351” Talent Program, 2020.

Institutional Review Board Statement: Not applicable.

Informed Consent Statement: Not applicable.

Data Availability Statement: The parking data could be found at https://doi.org/10.6084/m9 .figshare.16353411.v1 (accessed on 1 June 2021).

Acknowledgments: We thank the individuals who filled out the questionnaires. Essential information about the parking situation in the Information Department campus of Wuhan University was provided by Xiuqin Wei and is gratefully appreciated. We also thank Tinghua Ai very much for his advice on the paper.

Conflicts of Interest: The authors declare that they have no conflict of interest.

\section{Appendix A}

Questionnaire on campus parking environment.

Your university in 2019?

a. Wuhan University.

b. Other.

You spend most of your time in?

a. Information Department Campus.

b. Arts and Science Department Campus. 
c. Engineering Department Campus.

d. Medicine Department Campus.

Are you a student?

a. Yes, I am.

b. No, I am not.

Do you own your private car?

a. Yes, I do.

b. No, I do not.

Please comment on the parking situation in the Information Department Campus of Wuhan University.

a. Extremely chaotic.

b. Kind of chaotic.

c. Hard to comment.

d. Organized.

e. Very organized.

Please comment on the utilization of parking resources in the Information Department Campus of Wuhan University.

a. Overused (too much parking).

b. Slightly overused (a little too much parking).

c. Moderate.

d. Slightly underused.

c. Underused.

Does the current parking situation of the Information Department Campus of Wuhan University affect your life?

a. No.

b. A little.

c. Very.

Do you want the campus to further strengthen management of the parking situation? a. Yes.

b. I do not care.

c. No.

What do you think of the socialization of campus roads and campus parking spaces in Information Department Campus of Wuhan University to help alleviate poor traffic in the surrounding areas?
a. Agree.
b. I do not care.
c. Disagree.

\section{References}

1. Bjorklund, E.M. The Danwei: Socio-spatial characteristics of work units in China's urban society. Econ. Geogr. 1986, 62, 19-29. [CrossRef]

2. National Bureau of Statistics of China. 2020 China Statistical Yearbook; China Statistics Press: Beijing, China, 2020.

3. Wuhan Municipal Statistics Bureau. 2020 Wuhan Statistical Yearbook; China Statistics Press: Beijing, China, 2020.

4. Yin, C.; Shao, C.; Wang, X. Built environment and parking availability: Impacts on car ownership and use. Sustainability 2018, 10, 2285. [CrossRef]

5. Liu, Q.; Chen, P.; Sun, F. Parking policies in China's metropolises: Rationales, consequences, and implications. Urban Policy Res. 2018, 36, 186-200. [CrossRef]

6. Wang, R.; Yuan, Q. Parking practices and policies under rapid motorization: The case of China. Transp. Policy 2013, 30, 109-116. [CrossRef]

7. Shen, T.; Hong, Y.; Thompson, M.M.; Liu, J.; Huo, X.; Wu, L. How does parking availability interplay with the land use and affect traffic congestion in urban areas? The case study of Xi'an, China. Sustain. Cities Soc. 2020, 57, 102126. [CrossRef]

8. Zhuge, C.; Shao, C.; Li, X. Empirical analysis of parking behaviour of conventional and electric vehicles for parking modelling: A case study of Beijing, China. Energies 2019, 12, 3073. [CrossRef]

9. Chen, Q.; Wang, Y.; Pan, S. Characteristics of parking in central Shanghai, China. J. Urban Plan. Dev. 2016, $142,05015012$. [CrossRef] 
10. Dong, Y.-H.; Peng, F.L.; Bao, Z.H.; Qiao, Y.K. Identification of the spatial distribution pattern and driving forces of underground parking space based on multi-source data: A case study of Fuzhou City in China. Sustain. Cities Soc. 2021, 72, 103084. [CrossRef]

11. Bowerman, A. On-Campus Parking: Problems and Solutions. Master's Thesis, University of North Carolina at Chapel Hill, Chapel Hill, NC, USA, 2006.

12. Filipovitch, A.; Boamah, E.F. A systems model for achieving optimum parking efficiency on campus: The case of Minnesota State University. Transp. Policy 2016, 45, 86-98. [CrossRef]

13. Garcia, M.; Rose, P.; Sung, R.; El-Tawab, S. Secure smart parking at james madison university via the cloud environment (space). In Proceedings of the 2016 IEEE Systems and Information Engineering Design Symposium (SIEDS), Charlottesville, VA, USA, 29 April 2016; pp. 271-276.

14. Aoun, A.; Abou-Zeid, M.; Kaysi, I.; Myntti, C. Reducing parking demand and traffic congestion at the American University of Beirut. Transp. Policy 2013, 25, 52-60. [CrossRef]

15. Riggs, W. Dealing with parking issues on an urban campus: The case of UC Berkeley. Case Stud. Transp. Policy 2014, 2, 168-176. [CrossRef]

16. dell'Olio, L.; Cordera, R.; Ibeas, A.; Barreda, R.; Alonso, B.; Moura, J.L. A methodology based on parking policy to promote sustainable mobility in college campuses. Transp. Policy 2019, 80, 148-156. [CrossRef]

17. Balsas, C.J.L. Sustainable transportation planning on college campuses. Transp. Policy 2003, 10, 35-49. [CrossRef]

18. Campisi, T.; Torrisi, V.; Ignaccolo, M.; Inturri, G.; Tesoriere, G. University propensity assessment to car sharing services using mixed survey data: The Italian case study of Enna city. Transp. Res. Procedia 2020, 47, 433-440. [CrossRef]

19. Ribeiro, P.; Fonseca, F.; Meireles, T. Sustainable mobility patterns to university campuses: Evaluation and constraints. Case Stud. Transp. Policy 2020, 8, 639-647. [CrossRef]

20. Shannon, T.; Giles-Corti, B.; Pikora, T.; Bulsara, M.; Shilton, T.; Bull, F. Active commuting in a university setting: Assessing commuting habits and potential for modal change. Transp. Policy 2006, 13, 240-253. [CrossRef]

21. Meng, F.; Du, Y.; Chong Li, Y.; Wong, S.C. Modeling heterogeneous parking choice behavior on university campuses. Transp. Plan. Technol. 2018, 41, 154-169. [CrossRef]

22. Gurbuz, O.; Jauregui, X.; Cheu, R.L. Development of Demand and Pricing Models for University Campus Parking. In Proceedings of the Transportation Research Board 98th Annual Meeting, Washington, DC, USA, 13-17 January 2019.

23. Ajchariyavanich, C.; Ajchariyavanich, C.; Limpisthira, T.; Chanjarasvichai, N.; Jareonwatanan, T.; Phongphanpanya, W.; Wareechuensuk, S.; Srichareonkul, S.; Tachatanitanont, S.; Ratanamahatana, C.; et al. Park King: An IoT-based Smart Parking System. In Proceedings of the 2019 IEEE International Smart Cities Conference (ISC2), Casablanca, Morocco, 14-17 October 2019; pp. 729-734.

24. Huang, Z.; Xu, X.; Luo, Q.; Fang, D. Campus Parking Planning Based on Multisource Data Analysis-Taking Mafangshan Campus of Wuhan University of Technology as an Example. J. Phys. Conf. Ser. 2020, 1486, 052031. [CrossRef]

25. Mohandes, M.; Deriche, M.; Abuelma'atti, M.T.; Tasadduq, N. Preference-based smart parking system in a university campus. IET Intell. Transp. Syst. 2018, 13, 417-423. [CrossRef]

26. Singh, J.J.; Ravi, N.N.; Krishnan, P.S. Iot based parking sensor network for smart campus. Int. J. Eng. Technol. 2018, 7, 26-34. [CrossRef]

27. Ji, Z.; Ganchev, I.; O’Droma, M.; Zhang, X. A cloud-based intelligent car parking services for smart cities. In Proceedings of the 2014 XXXIth URSI General Assembly and Scientific Symposium (URSI GASS), Beijing, China, 16-23 August 2014; pp. 1-4.

28. Jhugroo, M.S.; Kataully, M.S.; Nagowah, S.D. Implementation of a Smart Parking System for a University Campus. In Progress in Advanced Computing and Intelligent Engineering; Springer: Berlin/Heidelberg, Germany, 2021; pp. 707-718.

29. Shang, H.; Wenji, L.I.N.; Huang, H. Empirical study of parking problem on university campus. J. Transp. Syst. Eng. Inf. Technol. 2007, 7, 135-140. [CrossRef]

30. Barata, E.; Cruz, L.; Ferreira, J.-P. Parking at the UC campus: Problems and solutions. Cities 2011, 28, 406-413. [CrossRef]

31. Wang, Z.; Zhou, W. Current situation and improvement strategy for campus parking in China. In Proceedings of the 2010 International Conference on Intelligent Computation Technology and Automation, Changsha, China, 11-12 May 2010; pp. 1075-1078.

32. Qiu, Y.; Zhao, C.; Deng, F.; Ji, Y.; Du, Y. Data-Driven Refined Management Strategy on Campus Parking: The Case of Tongji University. In Proceedings of the Transportation Research Board 97th Annual Meeting, Washington, DC, USA, 7-11 January 2018.

33. Chalermpong, S.; Ampansirirat, N. Modeling Chulalongkorn University campus parking demand. J. East. Asia Soc. Transp. Stud. 2011, 9, 566-574.

34. Panigrahi, S.; Kundu, A.; Sural, S.; Majumdar, A.K. Credit card fraud detection: A fusion approach using Dempster-Shafer theory and Bayesian learning. Inf. Fusion 2009, 10, 354-363. [CrossRef]

35. Xie, J.; Xiong, Z.Y.; Dai, Q.Z.; Wang, X.X.; Zhang, Y.F. A new internal index based on density core for clustering validation. Inf. Sci. 2020, 506, 346-365. [CrossRef]

36. Ozkok, F.O.; Celik, M. A new approach to determine Eps parameter of DBSCAN algorithm. Int. J. Intell. Syst. Appl. Eng. 2017, 5, 247-251. [CrossRef]

37. Gao, S.; Li, M.; Liang, Y.; Marks, J.; Kang, Y.; Li, M. Predicting the spatiotemporal legality of on-street parking using open data and machine learning. Ann. GIS 2019, 25, 299-312. [CrossRef] 
38. Fan, M.; Lv, J.; Yu, C.; Guo, Y.; Bian, Z.; Yang, S.; Yang, L.; Chen, Y.; Huang, Y.; Chen, B.; et al. Association Between Active Commuting and Incident Cardiovascular Diseases in Chinese: A Prospective Cohort Study. J. Am. Heart Assoc. 2019, 8, e012556. [CrossRef]

39. Barnett, A.; Mewburn, I.; Schroter, S. Working 9 to 5, not the way to make an academic living: Observational analysis of manuscript and peer review submissions over time. BMJ 2019, 367, 16460. [CrossRef]

40. Daggett, J.; Gutkowski, R. University transportation survey: Transportation in university communities. Transp. Res. Rec. 2003, 1835, 42-49. [CrossRef]

41. Miller, J.H. Transportation on College and University Campuses; Transportation Research Board: Washington, DC, USA, 2001.

42. Sundo, M.B.; Fujii, S. The effects of a compressed working week on commuters' daily activity patterns. Transp. Res. Part A Policy Pract. 2005, 39, 835-848. [CrossRef]

43. Lei, C.; Ouyang, Y. Dynamic pricing and reservation for intelligent urban parking management. Transp. Res. Part C Emerg. Technol. 2017, 77, 226-244. [CrossRef]

44. Yang, C.-F.; Ju, Y.H.; Hsieh, C.Y.; Lin, C.Y.; Tsai, M.H.; Chang, H.L. iParking-A real-time parking space monitoring and guiding system. Veh. Commun. 2017, 9, 301-305. [CrossRef]

45. Wang, C.; Zhang, H.; Yang, M.; Wang, X.; Ye, L.; Guo, C. Automatic parking based on a bird's eye view vision system. Adv. Mech. Eng. 2014, 6, 847406. [CrossRef]

46. Teh, S.L. Android Based Campus Smart Parking System Using Image Processing. Ph.D. Thesis, Tunku Abdul Rahman University College, Kuala Lumpur, Malaysia, 2019.

47. Shoup, D. Parking on a Smart Campus: Lessons for Universities and Cities; UCLA, School of Public Affairs: Los Angeles, CA, USA, 2005. 